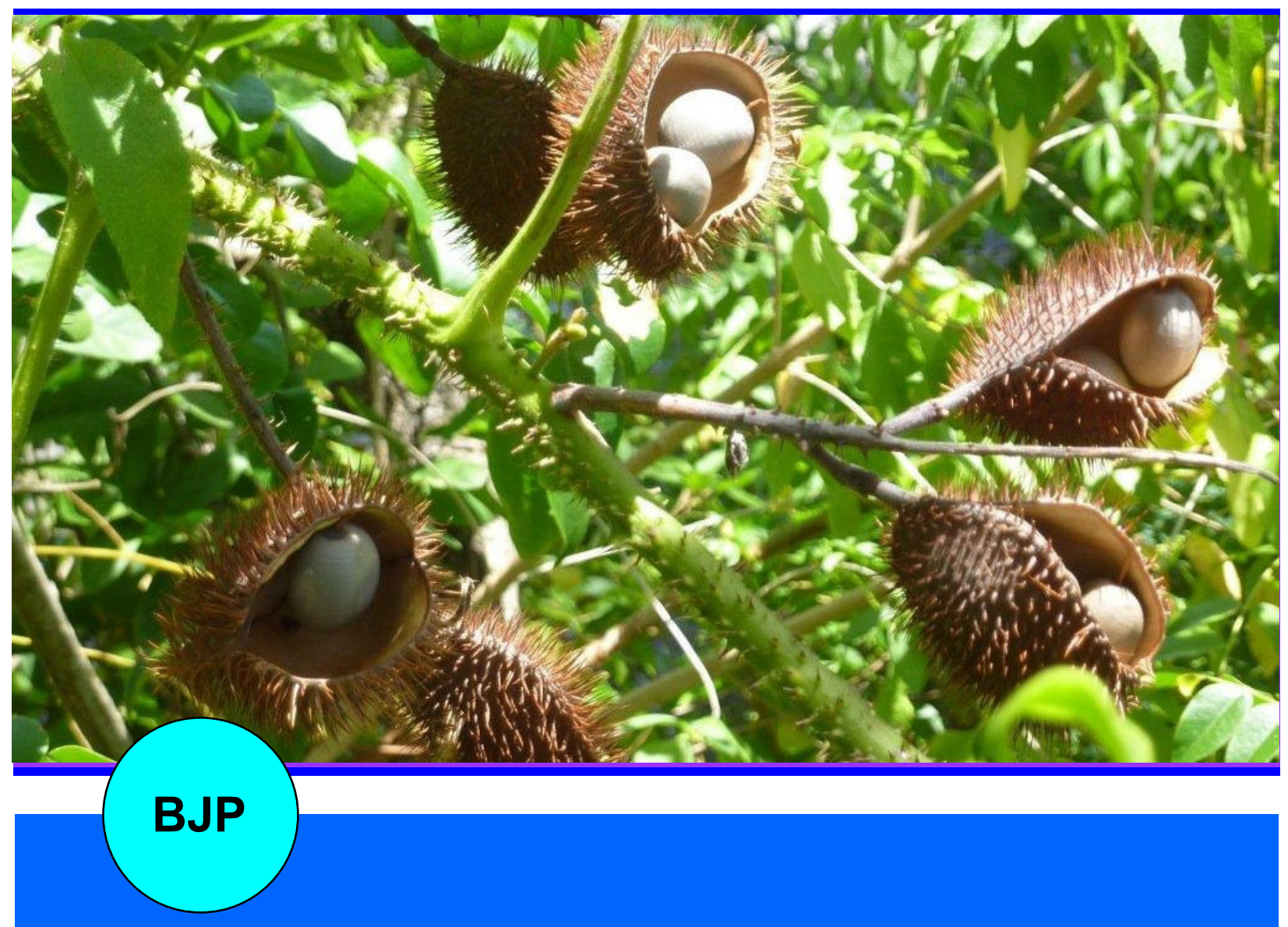

Bangladesh Journal of Pharmacology

Research Article

Diuretic effect of Caesalpinia bonduc in rats 


\section{Diuretic effect of Caesalpinia bonduc in rats}

\section{Ajay Khedkar, Yuvaraj D. Mandavkar, Gulab Shinde, Pallavi Khalure and Pravin Dere}

Department of Pharmacognosy and Phytochemistry, KLEUs College of Pharmacy, Belgaum, India.

\begin{tabular}{|c|c|}
\hline Article Info & \\
\hline Received: & 26 August 2011 \\
\hline Accepted: & 19 September 2011 \\
\hline Available Online: & 20 September 2011 \\
\hline DOI: $10.3329 /$ bjp.v & $6 \mathrm{i1} 1.8487$ \\
\hline Cite this article: & \\
\hline Khedkar A, Mand & davkar YD, Shinde \\
\hline G, Khalure P, Der & e P. Diuretic effect \\
\hline $\begin{array}{l}\text { of Caesalpinia bond } \\
\text { desh J Pharmacol. } 2\end{array}$ & $\begin{array}{l}\text { Huc in rats. Bangla- } \\
2011 ; 6: 61-63 \text {. }\end{array}$ \\
\hline
\end{tabular}

\section{Abstract}

The diuretic effect of aqueous and methanol extracts of the dried seeds of Caesalpinia bonduc was studied in normal rats. Extracts were administered orally at two doses and furosamide was used as standard drug. Urine volume was significantly increased by the two doses of aqueous and methanol extracts in comparison to control group. While the excretion of sodium was also increased by both extracts, potassium excretions were only increased by the aqueous and methanol extracts at a higher dose. The present study provides a quantitative basis for explaining the use of seeds extracts of $C$. bonduc as a diuretic agent.

\section{Introduction}

Caesalpinia bonduc L., commonly known as Nata Karanja, a prickly shrub found throughout the hotter parts of India, Myanmar and Sri Lanka, has grey, hard, globular shaped seeds with a smooth shining surface. Seeds consist of a thick, brittle shell with a yellowish white bitter fatty kernel (Nadkarni, 1954). Plant is reported to have multiple therapeutic properties like, anti-anaphylactic and antiviral (Dhar et al., 1968), antiasthmatic (Gayaraja et al., 1978), antiamebic and anti-estrogenic (Raghunathan and Mitra, 1982). Blood sugar lowering activity of C. bonduc has been primarily evaluated with significant result in rabbit (Rao et al., 1994) and rat models (Biswas et al., 1997; Sharma et al., 1997). In the present study, we examined the diuretic activity of $C$. bonduc seeds extracts.

\section{Materials and Methods \\ Plant material and identification}

C. bonduc seeds were collected in March 2008 from Sangli District, Maharashtra, India. Further taxonomic identification was conducted by Dr. P. G. Diwakar, Joint Director, BSI, Pune and by Dr. Harsha Hegde, research scientist, ICMR, Belgaum. A voucher specimen has been deposited in the herbarium (Kascb1 and RMRC 474 respectively). The seeds were dried, powdered and passed through 40-mesh sieve and stored in an airtight container for further use.

\section{Preparation of the seeds extracts}

The seeds were dried and size reduced to a coarse powder. The coarse powder was extracted in soxhlet extractor with methanol. The seeds coarse powder was also macerated with distilled water for 7 days of frequently shaking. The methanol and aqueous extracts were concentrated on rotary flash evaporator and vacuum dried over anhydrous sodium sulfate. The residue was reddish brown sticky mass $(16 \%, \mathrm{w} / \mathrm{w})$ (methanol extract) and (black brown for aqueous extract $13 \% \mathrm{w} / \mathrm{w})$.

\section{Animals}

Adult male Wistar rats, each in the weight range of 180$200 \mathrm{~g}$, were obtained from the Animal House. The animals were randomly kept in polypropylene cages and housed under standard conditions of temperature, humidity and dark light cycle (12/12 hours). The dose of animal were determine as per the OECED guideline no. 423 . 
Table I

Effect of extracts of seeds of Caesalpinia bonduc on urinary volume, diuretic index, conductivity and $\mathrm{pH}$

\begin{tabular}{|c|c|c|c|c|}
\hline Treatment $(\mathrm{mg} / \mathrm{kg})$ & $\begin{array}{l}\text { Urine volume } \\
\mathrm{mL} / 100 \mathrm{~g} / \text { hour }\end{array}$ & Diuretic index & Conductivity & $\mathrm{pH}$ \\
\hline Control & $4.0 \pm 0.1$ & ---- & $13.4 \pm 0.3$ & $7.4 \pm 0.2$ \\
\hline Furosemide (20) & $9.8 \pm 1.2^{b}$ & 2.5 & $15.3 \pm 0.3$ & $7.4 \pm 0.4$ \\
\hline Aqueous extract (150) & $6.3 \pm 0.2^{\mathrm{a}}$ & 1.6 & $14.0 \pm 1.4$ & $7.5 \pm 0.2$ \\
\hline Aqueous extract $(300)$ & $7.1 \pm 0.1^{b}$ & 1.8 & $14.9 \pm 1.1$ & $7.5 \pm 0.2$ \\
\hline Methanol extract (150) & $6.3 \pm 0.4^{\mathrm{a}}$ & 1.6 & $13.7 \pm 1.0$ & $7.3 \pm 0.2$ \\
\hline Methanol extract (300) & $6.9 \pm 0.3^{b}$ & 1.7 & $15.0 \pm 0.6$ & $7.3 \pm 0.4$ \\
\hline
\end{tabular}

\section{Experimental protocol}

All experimental protocols were approved by the Institutional Animal Ethical Committee of KLES's College of Pharmacy. Diuretic activity was determined following the methods (Kau et al., 1984), with minor modifications. The rats were randomly divided into six groups of six animals each as follows: (1) control- given $5 \mathrm{~mL} / \mathrm{kg}$ body weight of de-ionized water; (2) aqueous extract- $150 \mathrm{mg} / \mathrm{kg}$ body weight; (3) aqueous extract$300 \mathrm{mg} / \mathrm{kg}$ body weight; (4) methanol extract- $150 \mathrm{mg} /$ $\mathrm{kg}$ body weight; (5) methanol extract- $300 \mathrm{mg} / \mathrm{kg}$ body weight; and (6) furosemide- $20 \mathrm{mg} / \mathrm{kg}$ body weight. In all cases, the volume of the dose was administered 5 $\mathrm{mL} / \mathrm{kg}$ body weight. The animals were fasted overnight (18 hours) prior to the test but with free access to tap water only and then were given an oral loading of normal saline $(0.9 \%)$ of $0.05 \mathrm{~mL} / \mathrm{g}$ body weight. Immediately after administration, the rats were paired and placed in metabolism cages. Urine was collected in a graduated cylinder and its volume was recorded at 2 hours intervals for 8 hours. Cumulative urine excretion was calculated in relation to body weight and expressed as $\mathrm{mL} / 100 \mathrm{~g}$ body weight. Electrolyte $(\mathrm{Na}+$ and $\mathrm{K}+)$ concentrations, $\mathrm{pH}$ and conductivity were estimated from the urine sample of each pair of rats at the end of the experimental period (8 hours) and expressed as $\mathrm{mEq} / 100 \mathrm{~g}$ body weight. Measurement of urine output and analysis of electrolytes $\mathrm{Na}+$ and $\mathrm{K}+$ concentrations were measured using a Toshniwal group model TCM-35 flame photometer. The instrument was calibrated with standard solutions containing different concentrations of $\mathrm{Na}+$ and $\mathrm{K}+$. The conductivity was directly determined on fresh urine samples using a conductometer (Toshniwal group model TCM-15). $\mathrm{pH}$ was measured with a $\mathrm{pH}$ meter on fresh urine sample.

\section{Statistical analysis}

The results are expressed as mean values \pm S.E.M. Statistical comparison was carried out by analysis of variance (ANOVA). The difference between the means of treated groups and the non-treated control group was evaluated by the Bonferroni Multiple Comparisons
Test. The statistical analysis was carried out with software, prism 5 . The results were considered statistically significant when it was $\mathrm{p}<0.05$.

\section{Results}

Table I shows that the furosemide, increased urine volume by $146.73 \%$. The aqueous extract showed increase in urine volume by $58.79 \%(\mathrm{p}<0.01)$ and $78.89 \%$ $(\mathrm{p}<0.001)$ at dose of $150 \mathrm{mg} / \mathrm{kg}$ and $300 \mathrm{mg} / \mathrm{kg}$ respectively, compared to the control group, while for the methanol extract at $150 \mathrm{mg} / \mathrm{kg}$ and $300 \mathrm{mg} / \mathrm{kg}$ showed $58.54 \%(\mathrm{p}<0.01)$ and $72.61 \%(\mathrm{p}<0.001)$, increase in urine volume respectively. Changes in other parameters - conductivity and $\mathrm{pH}$ - were not significant when compared to control group.

Table II shows the urinary electrolyte content following the administration of the extracts. The dose of $150 \mathrm{mg} /$ $\mathrm{kg}$ aqueous extract produced a significant increase in $\mathrm{Na}^{+}$excretion, compared with the control group $(\mathrm{p}<$ 0.01 ). The dose of $300 \mathrm{mg} / \mathrm{kg}$ aqueous extract and furosemide produced a significant increase in the $\mathrm{Na}^{+}$ and $\mathrm{K}^{+}$excretion $(\mathrm{p}<0.001)$. However, $300 \mathrm{mg} / \mathrm{kg}$ of the methanol extract produced a significant increase in $\mathrm{Na}^{+}$ and $\mathrm{K}^{+}$excretion $(\mathrm{p}<0.001)$. Methanol extract at lower

\begin{tabular}{|c|c|c|}
\hline \multicolumn{3}{|c|}{ Table II } \\
\hline \multicolumn{3}{|c|}{$\begin{array}{l}\text { Effect of aqueous and methanol extracts of } C \text {. bon- } \\
d u c \text { on sodium and potassium excretion in urine }\end{array}$} \\
\hline \multirow[t]{2}{*}{ Treatment (mg/kg) } & \multicolumn{2}{|c|}{$\begin{array}{c}\text { Amount in urine } \\
(\mathrm{mEq} / 100 \mathrm{~g} / 8 \text { hours }) \times 10^{-2}\end{array}$} \\
\hline & Sodium & Potassium \\
\hline Control & $64.0 \pm 0.4$ & $17.0 \pm 1.4$ \\
\hline Furosemide (20) & $92.3 \pm 1.2^{\mathrm{b}}$ & $30.7 \pm 1.3^{b}$ \\
\hline Aqueous extract (150) & $65.4 \pm 1.8^{a}$ & $14.3 \pm 1.0$ \\
\hline Aqueous extract (300) & $90.3 \pm 2.3^{b}$ & $28.4 \pm 1.2^{\mathrm{a}}$ \\
\hline Methanol extract (150) & $58.3 \pm 1.3$ & $16.3 \pm 1.7$ \\
\hline Methanol extract (300) & $23.7 \pm 0.3^{b}$ & $20.2 \pm 0.8$ \\
\hline
\end{tabular}


dose fails to produce any significant activity in $\mathrm{Na}^{+}$and $\mathrm{K}^{+}$excretion.

\section{Discussion}

As per the review of literature the seeds of $C$. bonduc are used as diuretic agent, but no previous pharmacological or clinical study has been carried out to test the diuretic activity of this plant. Both the aqueous and methanol extracts of $C$. bonduc showed a dose-dependent increase in urine excretion. With respect to the aqueous extract, the maximum increase in urinary excretion was produced at $300 \mathrm{mg} / \mathrm{kg}$ compared while the methanol extract. The specific conductivity, which is an indirect measure of the ionic content of the urine, was increased in a dose-dependent manner in all the extracts-treated groups. Thus the diuretic effects of both extracts are indicated by increase in both water excretion and excretion of sodium and potassium. The active principles responsible for the diuretic effects of the extracts of this plant have not yet been elucidated but preliminary phytochemical analysis of the extracts revealed the presence of polar compounds such as flavonoids and steroidal compounds. Phytochemical investigation of seeds of $C$. bonduc has reveals the presence of flavanoids, tannin phenolic compounds and triterpenoids. These constituents may be responsible, at least in part, for the observed diuretic activity and that they may act individually or synergistically. Previous studies have demonstrated also that there are several compounds which could be responsible for the plants diuretic effects such as flavonoids, saponins or organic acids (Maghrani et al., 2005). The effect may be produced by stimulation of regional blood flow or initial vasodilation (Stanic and Samarzija, 1993), or by producing inhibition of tubular reabsorption of water and anions (Pantoja et al., 1993), the result in both cases being diuresis. The increased sodium and water excretion activity also provides strong basis for its proved anti-hypertensive action (Jouad et al., 2001).

In conclusion, this study provide a quantitative basis to explain the traditional folkloric use of C. bonduc as a diuretic agent in Moroccan population.

\section{References}

Biswas TK, Bandyopadhyay S, Mukherjee B, Sengupta BR. Oral hypoglycemic effect of Caesalpinia bonducella. Int J Pharmacog. 1997; 35: 261-64.

Dhar ML, Dhar MM, Dhawan BN, Mehrotra BN, Roy C. Screening of Indian plants for biological activity. Indian J Exp Biol. 1968; 6: 232-47.

Gayaraja S, Shinde S, Agarwal SL. Antiasthmatic properties of Caesalpinia bonducella leaves. Indian J Pharmacol. 1978; 10: 86-89.

Jouad H, Haloui M, Rhiouani H, El Hilaly J, Eddouks M. Ethnobotanical survey of medicinal plants used for the treatment of diabetes, cardiac and renal diseases in the North centre region of Morocco (Fez-Boulemane). J Ethnopharmacol. 2001; 77: 175-82.

Kau ST, Keddi, JR, Andrews D. A method for screening diuretic agents in the rats. J Pharmacol Meth. 1984; 11: 6775 .

Maghrani M, Zeggwagh N, Haloui M, Eddouks M. Acute diuretic effect of aqueous extract of Retama raetam in normal rats. J. Ethnopharmacol. 2005; 99: 31-35.

Nadakarni AK, Nadakarni KR. Indian Materia Medica; Bombay, Popular Prakashan, 1999, p 226.

OECD. Guidelines for testing of chemicals. Revised draft guidelines 423 . Acute oral toxicity class method. October 2000.

Pantoja CV, Chiang LCH, Norris BC, Concha JB. Diuretic, natriuretic and hypotensive effects produced by Allium sativum (garlic) in anaesthetized dogs. J Ethnopharmacol, 1993; 31: 325-31.

Raghunathan, K, Mitra R. Pharmacognosy of indigenous drugs. New Delhi, Central Council for Research in Ayurveda and Siddha, 1982, pp 484-510.

Rao VV, Dwivedi SK, Swarup D. Hypoglycemic effect of Caesalpinia bonducella in rabbits. Fitoterapia 1994; 65: 245-47.

Sharma SR, Dwivedi SK, Swarup D. Hypoglycemic, antihyperglycemic and hypolipidemic activities of Caesalpinia bonducella seeds in rats. J Ethnopharmacol. 1997; 58: 39-44.

Stanic G, Samarzija I. Diuretic Activity of Satureja montana subsp. montana extracts and oil in rats. Phytother Res. 1993; 7: 363-66. 